\title{
Review
}

\section{My 25 Stimulating Years with DBS in Parkinson's Disease}

\author{
Marwan Hariz ${ }^{\mathrm{a}, \mathrm{b}, *}$ \\ a Simon Sainsbury Chair of Functional Neurosurgery, Unit of Functional Neurosurgery, \\ UCL-Institute of Neurology, Queen Square, London, UK \\ ${ }^{\mathrm{b}}$ Department of Clinical Neuroscience, Stereotactic Surgery, Umeå University, Umeå, Sweden
}

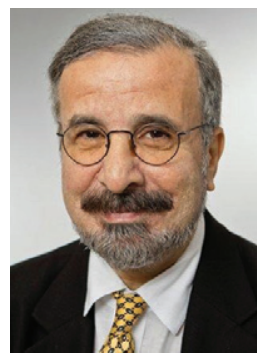

Marwan Hariz received the Baccalauréat in Beirut (Lebanon), then studied medicine in Reims (France) and in Umeå (Sweden). He trained in neurosurgery in Umeå with Lauri Laitinen as main mentor. He received a PhD in 1990 in stereotactic neurosurgery. In 2002, he was recruited as Professor to the United Kingdom's first Chair of Functional Neurosurgery at the National Hospital for Neurology and Neurosurgery, and the University College London Institute of Neurology, Queen Square (London, UK), where he contributed to the establishment of a multidisciplinary clinical and academic Unit of Functional Neurosurgery. His main interests are in brain imaging and in surgery for movement disorders and psychiatric illness, as well as in critical appraisal of published literature in these areas.

\begin{abstract}
The year 2017 marks the 30th anniversary of the birth of modern deep brain stimulation (DBS), which was introduced by Benabid, Pollak et al. in 1987, initially targeting the motor thalamus to treat tremor, and subsequently targeting the subthalamic nucleus (STN) for treatment of symptoms of advanced Parkinson's disease (PD). STN DBS is undoubtedly "the most important discovery since levodopa", as stated by David Marsden in 1994. In 2014, The Lasker-DeBakey Clinical Medical Research Award to "honor two scientists who developed deep brain stimulation of the subthalamic nucleus", was bestowed upon Benabid and DeLong. STN DBS remains today the main surgical procedure for PD, due to its effectiveness in ameliorating PD symptoms and because it is the only surgical procedure for PD that allows a radical decrease in medication. Future improvements of DBS include the possibility to deliver a "closed-loop", "on demand" stimulation, as highly preliminary studies suggest that it may improve both axial and appendicular symptoms and reduce side effects such as dysarthria. Even though DBS of the subthalamic nucleus is the main surgical procedure used today for patients with PD, all patients are not suitable for STN DBS; as a functional neurosurgeon performing since more than 25 years various surgical procedures the aim of which is not to save life but to improve the patient's quality of life, I consider that the surgery should be tailored to the patient's individual symptoms and needs, and that its safety is paramount.
\end{abstract}

Keywords: Parkinson's disease, deep brain stimulation, subthalamic nucleus, globus pallidus, thalamus, quality of life, pallidotomy, stereotactic neurosurgery, safety

\footnotetext{
${ }^{*}$ Correspondence to: Prof. Marwan Hariz, Unit of Functional Neurosurgery, Box 146, Institute of Neurology, Queen Square, London, WC1N 3BG, UK. Tel.: +44 7985642 852; Fax: +44 20 7419 1860; E-mail: m.hariz@ucl.ac.uk.
} 
"I used to wonder years ago when the anxiety, tension, and pain of the decision... would disappear. I now know the answer to that question. When? Never - that's when."

Irving S. Cooper: The Vital Probe. My life as a brain surgeon (1981).

\section{INTRODUCTION}

My mentor Lauri Laitinen (1928-2005), - the neurosurgeon from Umeå, Sweden, who pioneered the renaissance of surgery for Parkinson's disease (PD) in the mid 1980s by resurrecting Leksell's posteroventral pallidotomy [1] - wrote in 2003, in his last publication pertinent to $\mathrm{PD}$ :

"In my opinion, DBS of the subthalamic nucleus represents a most important step of the last decade in the surgical treatment of Parkinson's disease. We owe a great debt to Professor Alim-Louis Benabid for his intelligence and courage to have begun the implantation of chronic electrodes in the STN" [2].

It was the discovery of Bergman, Wichman and DeLong in 1990 [3] that lesions of the subthalamic nucleus (STN) alleviated experimental parkinsonism in the MPTP monkey model of PD, that paved the way to target that nucleus with high frequency Deep Brain stimulation (DBS) in humans.

The first paper about DBS of the STN (unilateral surgery in one patient) was published in French in 1993 [4] and the second paper describing three patients bilaterally operated was published in the Lancet in 1995 [5]. However, already in March 1994, at the 11th Parkinson's Disease symposium in Rome, Grenoble neurologist Pierre Pollak presented the results of DBS of the STN, including a video of the first patients. The late Professor David Marsden, who was present in the audience, publicly stated then that this was "the most important discovery since levodopa" [6]. The honeymoon had begun, and in some respect, it is still lasting. Here I retrace my 25 years of clinical and academic activity in DBS for PD, highlighting its advantages and its shortfalls, as well as providing a critical appraisal of the pertinent literature on the subject of surgery for PD.

\section{THE EARLY EUPHORIA}

2017 marks the 30th birthday anniversary of modern DBS. It was in 1987 that Benabid, Pollak et al. from Grenoble published their seminal paper on thalamic DBS for tremor [7]. This procedure did not make a dent in the field at that time because it was only directed at the ventral intermediate nucleus (VIM) of the thalamus for treatment of tremor. By contrast, the revival of posteroventral pallidotomy, that happened at roughly the same period, addressed the whole triad of cardinal PD symptoms (bradykinesia, rigidity and tremor) as well as L dopa-induced dyskinesias. Hence, Laitinen's posteroventral pallidotomy was the main surgical procedure performed and published worldwide in the 1990s [8]. Towards the turn of the millennium STN DBS had gained momentum, and because it could be done bilaterally in one session and was efficient for bradykinesia, rigidity and tremor, and allowed a radical decrease of medications, it almost completely superseded pallidotomy. Initially, there were some reports that STN DBS could even be neuroprotective, but this has unfortunately not been confirmed [9].

Beginning in the early 1990s, I started to perform DBS and gradually shifted from performing mainly ablative surgery (pallidotomy, thalamotomy) towards performing mainly DBS, first Vim DBS for tremor and eventually pallidal and STN DBS for advanced PD. This shift was driven by the widely held view that DBS was non-destructive, adaptable, safe and reversible, and could be done bilaterally in same surgical session [10] (which was not possible in ablative surgery). By the year 2000, some 50-60 patients had had thalamic DBS at Umeå University Hospital, where I was based, and about 12 patients had received pallidal or STN DBS. In 1999, I published one of the first reports describing the development of tolerance to VIM thalamic DBS for tremor and the appearance of severe rebound upon stopping stimulation [11]. In 2000, I published an illustrative case report about one of the first patients of the STN DBS series, who had preoperatively some cognitive decline and speech problems, and in whom there was obvious discrepancy between a striking amelioration of Parkinsonian symptoms and a negative effect on the quality of life due to two side effects of STN DBS: dysarthrophonia and increasing dementia [12]. This was one of the first published reports drawing attention to the risks of bilateral STN DBS on cognition and speech in patients who present preoperatively with symptoms in these domains.

The real and universal breakthrough of DBS in STN and in DBS in the globus pallidus internus (GPi) took place following the publication of the worldwide multicenter trial in the New England Journal of Medicine in September 2001, which remains one of the most quoted in the field of DBS [13]. This 
was the paper on the basis on which DBS in STN and GPi was approved by the United States Food and Drug Administration. Something that was eyebrowraising in that paper, was that in Table 5, describing adverse events, the authors mentioned only one single stimulation-induced dysarthria in the 102 bilateral STN DBS patients and zero dysarthria in the 41 bilateral GPi DBS patients. This startlingly low level of side effects enticed me to write a Letter to the Editor pointing out this lapsus and I concluded my letter stating that "Deep-brain stimulation of the basal ganglia is an efficient treatment for Parkinson's disease, but this method may lose credibility if its side effects are not properly accounted for" [14]. Today, it is undisputed that dysarthria is one of the main side effects of bilateral DBS in the STN, varying between zero and $97 \%$ depending on how evaluation is done, when after surgery and depending of course on electrode location in the target area, among other variables [15-18].

\section{STN DBS: SELECTION CRITERIA}

In the process of elucidating the best selection criteria for patients for STN DBS, several studies correlated the improvement following surgery to various patient-specific factors. The most notable were papers by Charles et al. from Grenoble [19] and Welter et al. from Salpêtrière in Paris [20] confirming that a good preoperative response to L-dopa, a shorter disease duration, a good cognitive status and a younger age of patients were highly predictive of a good response to STN DBS. Subsequently, reports started to appear about behavioural side effects of DBS such as apathy, depression, mania, marital conflicts, cognitive decline, behavioural changes, etc [21-26], all of which did put further constraints on which patients would be considered eligible for this highly efficient procedure. Despite the stringent selection criteria, several centres only perform STN DBS and do not offer any other surgery if patients do not fulfil criteria for STN DBS. The concept of a surgical procedure tailored to the status and symptoms of the patient, that I introduced in 2000 [27] fell for many years on deaf ears before eventually being recognized and proposed by some authors [15, 28-30], and before the Task Force of the International Movement Disorders Society updated its recommendations in 2013 declaring that both STN DBS, GPi DBS and pallidotomy were evidence-based and approved for surgical treatment of PD [31].
Be it as it may, STN DBS remains today the main surgical procedure for PD, mainly, but not solely, due to its effectiveness in ameliorating PD symptoms and because it is the only surgical procedure for PD that allows a radical decrease in medication even in patients with advanced PD. The well publicized neurological, behavioural, and other side-effects of STN DBS, such as obsessive compulsive disorders, have in fact contributed to better understanding of the pathophysiology and connectivities of the STN and its surrounding area, and has drawn researchers from allied areas such as psychiatry and behaviour to study the role of DBS in these conditions [32].

\section{MICROELECTRODE RECORDING OR NOT?}

In a paper from Toulouse published in 2007, the authors evaluated the outcome of microelectrodeguided STN DBS in relation to age of the patients [33]: out of 45 consecutive patients aged $40-73$ years, four patients had symptomatic cerebral bleeding of whom two patients, 71 and 69 years old, "experienced cerebral bleeding and died". Despite this (in my opinion unacceptable) $4.5 \%$ surgical mortality, the authors did not deal with what went wrong at surgery. The issue of surgical morbidity and mortality is ever present in the discussion on surgical technique. I have never endorsed the technique of microelectrode recording (MER) in DBS other than as a scientific tool to be used in a research setting on a limited number of patients, with their informed consent, in order to answer specific scientific questions [34]. This is because the available literature demonstrates that repeated penetrations of sharp microelectrodes along several tracks in the brain do indeed increase the surgical risks including haemorrhage, death, pneumocephalus, infections, as well as increasing surgical time and costs [34-38], without providing a measurable better outcome in terms of improved UPDRS scores compared to techniques that do not use MER. A meta-analysis by Zrinzo et al. of all DBS publications with more than 40 patients has shown that MER results in far more haemorrhage than image-guided DBS [38]. Indeed, some of those who were most enthusiastic about MER DBS have now abandoned this technique in favour of image-guided DBS performed in patients either awake or under general anaesthesia [39, 40]. The technique of stereotactic MRI-guided and stereotactic MRI-verified DBS that relies on individual 
imaging of the brain target, and individual imaging of the electrode in situ postoperatively, that I developed in Sweden in the early 1990s, and introduced to Queen Square 15 years ago [41-44], has resulted in zero surgical mortality in well over 1000 operated patients.

\section{THE "EARLYSTIM” TRIALS}

The "logical" conclusion that some have drawn from the fact that younger patients with short disease duration and good response to L-dopa would constitute better candidates for STN DBS, was that STN DBS should be performed at an earlier stage of the disease. Instead of the typical 11-13 years or more of disease duration before STN DBS [45, 46], Shüpbach et al. from Salpêtrière suggested performing surgery after about 7 years of disease, just when complications start to appear. In a report from 2007 [47], they followed 10 patients operated on "early" for 18 months and compared their outcome with 10 patients on best medical treatment. Only the operated patients exhibited improvement in UPDRS motor scores, in dyskinesia scores and in quality of life $(\mathrm{QoL})$, and were able to decrease their daily doses of dopaminergic drugs by $57 \%$. This led to the famous German-French "Earlystim" multicenter in 2013, with 2-year follow up showing better QoL in STN DBS patients than in matched patients receiving best medical treatment [48]. This study generated controversy with editorials and commentaries. The Editor of Lancet Neurology asked me to provide an editorial comment, in which I wrote: "There is no doubt that in the short to medium term, patients with Parkinson's disease who receive surgery will generally experience less severe symptoms than those who remain only on best medical treatment, regardless of disease stage at baseline and even regardless of what kind of surgery they receive (DBS or pallidotomy)" [49]. Given the heterogeneity of PD and also heterogeneity of long term benefit from STN DBS, I also wrote that "We do not know in the long term who will continue to do well and who will exhibit the issues well known to affect patients on long-term STN neurostimulation, such as refractory axial problems (speech, balance, and gait) and cognitive problems." [49]. I was comforted that my careful attitude towards offering an invasive procedure such as DBS before it is really warranted was supported by neurologists who were the very pioneers of STN DBS [50]
In any case, the "Earlystim" trial, that was successful precisely because it was conducted in highly selective and highly experienced centers, was used widely in Medtronic's adverts "Medtronic DBS EARLYSTIM" blasting the message "Timing is everything Why wait?"

Even more disturbing is the launch at Vanderbilt University of a pilot trial for STN DBS even earlier in the course of the disease [51]. The authors included 30 patients, 15 to receive DBS and best medical treatment, and 15 to continue on only best medical treatment. Patient selection included a diagnosis of idiopathic PD with a duration of disease of more than 6 months but less than 2 years, a Hoehn \& Yahr Stage of II when off medication, and the patients should not exhibit fluctuations or dyskinesias. Two of the DBS operated patients suffered "serious adverse events" including one who was left with a permanent deficit following basal ganglia infarction [51]. Despite that, the authors concluded that their study "met its primary endpoint related to safety, demonstrating that chronic stimulation does not produce greater declines in motor function compared to the control group". In a Letter to the Editor [52] I wondered whether the rationale for this study was to demonstrate that STN DBS does not make people with PD worse? As a functional neurosurgeon who dreads most of all a complication from my surgery, a surgery-related basal ganglia infarction in one out of 15 operated patients who did not even need surgery in the first place, is simply unacceptable.

\section{STN DBS OR GPI DBS?}

Even though STN DBS has been, and still is, the most published surgical procedure for $\mathrm{PD}$, it has been debated whether GPi DBS is equally effective [30, 53]. Proponents of GPi DBS, mostly in the US [15, 54-56], held the belief that it might be more lenient than STN DBS in terms of behavioural side-effects, while maintaining the same efficacy. Since efficacy on motor symptoms has been the main driver for the use of DBS, a multicenter study was designed to test which of the two procedures, STN DBS or GPi DBS, is most efficient for PD motor symptoms. This randomized trial [57] showed that both procedures showed similar results at 2 years, with 25-28\% improvement in the off-medication state, rated on the motor part of UPDRS. This surprisingly modest improvement is by any standard suboptimal, 
especially for STN DBS, compared to earlier work. Incidentally, this reported 25-28\% improvement was in fact very similar to the extent of improvement in randomized studies on unilateral pallidotomy, which was the main surgical procedure for PD in the 1990s [58-60].

\section{GENDER DIFFERENCES IN SURGERY FOR PD}

Another issue that caught the attention of our team was the gender distribution of PD patients undergoing surgery. It started by the observation that among all patients operated for PD at Umeå University Hospital since the start of the Neurosurgery department in 1969 , men were twice as many as women regardless of surgical procedure (thalamotomy, pallidotomy or DBS). This led to a comprehensive review of the international literature published between January 1985 and February 1999, focusing on gender distribution of PD patients undergoing stereotactic surgery. Regardless of the geographical origin of the publication and the surgical procedure, there were at least twice as many men with PD who had surgery as women [61]. A subsequent further review of more recent literature (2000-2009) limited to STN DBS showed similar results [62].

\section{THE LONG-TERM RESULTS OF DBS}

Publications describing long term outcomes of surgery for PD are scarce. In 2001, I published the first report on very long term (10 year) results of pallidotomy [63]. The main conclusion of that paper was: "The long term effect of posteroventral pallidotomy (PVP) on dyskinesias was not only curative but also appeared to be prophylactic. Further progression of axial and akinetic symptoms, and an eventual decline in cognition together with other concomitant illnesses, contributed to increased disability in several patients." [63]. Indeed several studies have described "striking similarities" between pallidotomy and STN DBS at very long-term follow-up [64] with progress of "axial and akinetic symptoms", "cognitive decline" and "comorbities" [65-67]. These were mainly attributed to progress of the disease with appearance of non-dopaminergic features, while DBS still provided good control for other symptoms (see below).

\section{STN DBS CREATES A NEW PHENOTYPE OF PD}

Hence, in some patients, long term STN DBS does result in a dissociation between a preserved good effect on symptoms of the upper limbs, especially tremor and rigidity, and a deterioration of axial and akinetic symptoms [67]. While this is not proof that STN DBS postpones later stages of the disease, it suggests that the procedure results in late stage PD patients who do not shake, and who exhibit less rigidity and bradykinesia in the hands, but who experience difficulties with walking, and exhibit freezing episodes, falls, and cognitive decline [65]. This postSTN DBS PD phenotype, that is widely recognized today, was first described by Paul Bejjani et al. in 2008 [68].

\section{FUTURE OF DBS FOR PD}

Notwithstanding the current trials using DBS in many areas of Neurology and Psychiatry, PD remains the main indication for DBS. Moreover, DBS will remain the main surgical procedure used in $\mathrm{PD}$ patients, for the foreseeable future [32]. Even after 30 years, the debate continues concerning several aspects of DBS in PD. For example, is the STN or GPi the most appropriate brain target? Should surgery be performed early or late in disease? Should one use microelectrode recording during surgery or not? Should DBS surgery be performed with the patient awake or asleep?

New medical device companies have entered the DBS market and new technological advances are being introduced [69]. New DBS leads enabling the current to be directed in a specific direction perpendicular to the axis of the lead, so called directional DBS, are being tested [70-72], with the hope of avoiding side effects by focusing the high frequency stimulation at the brain target aimed at and away from structures adjacent to it, and enabling the shaping the electrical current to "conform" to the anatomy of the target. Rechargeable stimulators are now available with a total battery life reported to be between 9 and 25 years, provided they are recharged regularly. It remains to be seen whether these technological advances will improve the outcome compared to conventional DBS leads, and conventional stimulation.

Perhaps the most exciting advance for the future of DBS in PD will be the ability to provide closedloop "on demand" stimulation. A delivery of high 
frequency electrical current to the brain target, guided by the physiological state of the patient, will enable stimulation to be supplied only when required to "block" the pathological neuronal firing responsible for the cardinal symptoms of the patient. Our group at Queen Square [73], demonstrated that when the typical 130-Hz stimulation is applied in a fluctuating PD patient who happens to be in a good 'on' state thanks to medication, the performance on finger tapping scores deteriorates slightly, whereas when that patient is in an off motor state, STN DBS results in improved tapping scores. In other words, STN DBS can negatively interfere with 'well functioning basal ganglia circuitry' when the fluctuating patient is in a clinical status that does not 'need' DBS at that particular time. The findings of that study suggested that 'on demand' DBS, aka "adaptive DBS" (i.e., DBS triggered by the level of pathological local field potential Beta activity) would be a more effective way of delivering stimulation. This theory has subsequently been tested in a collaboration between our group and Peter Brown's group in Oxford, showing that in the acute phase, during the first few days after surgery when the electrodes are externalised, an adaptive stimulation triggered by the Beta activity of the STN was more efficient than conventional stimulation, and with a 50\% reduction in stimulation time and a corresponding reduction in energy requirements [74]. Our further experiments with adaptive DBS showed that it can improve both axial and appendicular symptoms and can track the need for stimulation across drug states [75], as well as reduce side effects such as dysarthria, compared to conventional continuous stimulation [76]. It remains to be seen whether these highly preliminary results, obtained during a short time frame in experimental settings of adaptive stimulation a few days after surgery, will remain valid during chronic DBS and in the long term.

\section{CONCLUSIONS}

Despite all its associated problems, STN DBS remains today the main surgical procedure for PD, mainly, but not solely, due to its effectiveness in ameliorating PD symptoms, and because it is the only surgical procedure for PD that allows a radical decrease in medication.

With over 150000 patients operated on worldwide, DBS, especially DBS in the STN, is by far the most popular surgical procedure for PD. However, it must be kept in mind that the great majority of PD patients worldwide who would need surgery have no access to DBS. This is mainly due to financial reasons, but also due to the decline of ablative stereotactic surgery such as pallidotomy even though it has been shown that unilateral pallidotomy does not harbour more complications than DBS [77, 78].

DBS for PD is here to stay and it will continue to fascinate scientists and clinicians alike. A PubMed search performed on February 3d, 2017, using the search words "deep brain stimulation" and "Parkinson's disease" yielded 3731 articles. If "deep brain stimulation" is associated to "subthalamic nucleus", the PubMed search provides 2992 papers. This is a testimony of the scientific importance of DBS and of the STN, and indeed the 2014 Lasker-DeBakey Clinical Medical Research Award honouring Alim-Louis Benabid and Mahlon DeLong stated explicitly that it was delivered to them to "honor two scientists who developed deep brain stimulation of the subthalamic nucleus".

Despite the several decades of activity in DBS for PD, many controversies are still not resolved, many developments of the technique are being trialled and many challenges remain. Notwithstanding these, the fundamental issues of PD remain: How to tackle the progress of disease, especially the L-doparefractory axial symptoms, affecting speech, gait and balance, and the cognitive decline? In the meantime, the improvement brought by DBS to the quality of life of many patients is beyond doubt, and DBS and other surgical procedures, can be invaluable in treating motor and other symptoms due to the nigrostriatal degeneration, allowing the PD patient to enjoy an extended period of good quality of life.

For me, DBS, especially DBS for PD, represents a happy marriage between neurology and neurosurgery. In 2003 I baptised the child of that marriage: "Interventional Neurology" [8].

\section{ACKNOWLEDGMENTS}

The author and the Unit of Functional Neurosurgery at the UCL Institute of Neurology are supported by the Parkinson Appeal, UK, and the Monument Trust. I am indebted to my late neurosurgical mentors Lauri Laitinen and Harald Fodstad. I am also indebted to the former director of the Institute of Neurology (IoN) at Queen Square, and former vice-Provost of UCL, Professor Richard Frackowiak for having created the multidisciplinary Unit of Functional Neurosurgery, dedicated to DBS. I also 
wish to thank my previous and current colleagues at Umeå University Hospital, especially Professor Patric Blomstedt and his team, and of course my current colleagues and the whole multidisciplinary Team at the Unit in London, especially pioneer DBS neurologist Patricia Limousin, neurologist Tom Foltynie and neurosurgeon Ludvic Uriel Zrinzo.

\section{CONFLICT OF INTEREST}

The author has received honoraria and travel expenses from the Deep Brain Stimulation industry (Medtronic, StJude, Boston Scientific) for presenting talks at meetings.

\section{REFERENCES}

[1] Laitinen LV, Bergenheim AT, \& Hariz MI (1992) Leksell's posteroventral pallidotomy in the treatment of Parkinson's disease. J Neurosurg, 76, 53-61.

[2] Laitinen LV (2001) Surgical treatment for Parkinson's disease over the last decade. Adv Neurol, 86, 455-460.

[3] Bergman H, Wichmann T, \& DeLong MR (1990) Reversal of experimental parkinsonism by lesions of the subthalamic nucleus. Science, 249, 1436-1438.

[4] Pollak P, Benabid AL, Gross C, Gao DM, Laurent A, Benazzouz A, Hoffmann D, Gentil M, \& Perret J (1993) Effects of the stimulation of the subthalamic nucleus in Parkinson disease. Rev Neurol (Paris), 149, 175-176.

[5] Limousin P, Pollak P, Benazzouz A, Hoffmann D, Le Bas JF, Broussolle E, Perret JE, \& Benabid AL (1995) Effect of parkinsonian signs and symptoms of bilateral subthalamic nucleus stimulation. Lancet, 345, 91-95.

[6] Pollak P, \& Krack P (2007) Deep-brain stimulation for movement disorders. In Parkinson's Disease and Movement Disorders. 5th ed, Jankovic J, Tolosa E, eds. Lippincott Williams \& Wilkins, Philadelphia, PA, pp. 653-691.

[7] Benabid AL, Pollak P, Louveau A, Henry S, \& de Rougemont J (1987) Combined (thalamotomy and stimulation) stereotactic surgery of the VIM thalamic nucleus for bilateral Parkinson disease. Appl Neurophysiol, 50, 344-346.

[8] Hariz MI (2003) From functional neurosurgery to interventional neurology: A review of publications on thalamotomy, pallidotomy and DBS, between 1966 and 2001. Mov Disord, 18, 845-852.

[9] Harnack D, \& Kupsch A (2010) The impact of subthalamic deep brain stimulation on nigral neuroprotection - myth or reality? Neuromodulation, 13, 160-167.

[10] Siegfried J, \& Lippitz B (1994) Bilateral chronic electrostimulation of ventroposterolateral pallidum: A new therapeutic approach for alleviating all parkinsonian symptoms. Neurosurgery, 35, 1126-1129.

[11] Hariz MI, Shamsgovara P, Johansson F, Hariz G-M, \& Fodstad F (1999) Tolerance and tremor-rebound following long-term chronic thalamic stimulation for Parkinsonian and essential tremor. Stereotact Funct Neurosurg, 72, 208218.

[12] Hariz MI, Johansson F, Shamsgovara P, Johansson E, Hariz G-M, \& Fagerlund M (2000) Bilateral subthalamic nucleus stimulation in a Parkinsonian patient with preoperative deficits in speech and cognition: Persisting improvement in mobility but increased dependency. A case study. Mov Disord, 15, 136-139.

[13] The Deep-Brain Stimulation for Parkinson's Disease Study, Group (2001) Deep brain stimulation of the subthalamic nucleus or the pars interna of the globus pallidus in Parkinson's disease. $N$ Engl J Med, 345, 956-963.

[14] Hariz MI, \& Fodstad H (2002) Deep brain stimulation in Parkinson's disease. Letter to the Editor New Engl J Med, 346, 452.

[15] Bronstein JM, Tagliati M, Alterman RL, Lozano AM, Volkmann J, Stefani A, Horak FB, Okun MS, Foote KD, Krack P, Pahwa R, Henderson JM, Hariz MI, Bakay RA, Rezai A, Marks WJ Jr, Moro E, Vitek JL, Weaver FM, Gross RE, \& DeLong MR (2011) Deep brain stimulation for Parkinson disease: An expert consensus and review of key issues. Arch Neurol, 68, 165-172.

[16] Piboolnurak P, Lang AE, Lozano AM, Miyasaki JM, SaintCyr JA, Poon YY, Hutchison WD, Dostrovsky JO, \& Moro E (2007) Levodopa response in long-term bilateral subthalamic stimulation for Parkinson's disease. Mov Disord, 22, 990-997.

[17] Wertheimer J, Gottuso AY, Nuno M, Walton C, Duboille A, Tuchman M, \& Ramig L (2014) The impact of STN deep brain stimulation on speech in individuals with Parkinson's disease: The patient's perspective. Parkinsonism Relat Disord, 20, 1065-1070.

[18] Moro E (2014) Parkinson disease: Let's listen to patients with PD after deep brain stimulation. Nat Rev Neurol, 10, 550-552.

[19] Charles PD, Van Blercom N, Krack P, Lee SL, Xie J, Besson G, Benabid AL, \& Pollak P (2002) Predictors of effective bilateral subthalamic nucleus stimulation for PD. Neurology, 59, 932-934.

[20] Welter ML, Houeto JL, Tezenas du Montcel S, Mesnage V, Bonnet AM, Pillon B, Arnulf I, Pidoux B, Dormont D, Cornu P, \& Agid Y (2002) Clinical predictive factors of subthalamic stimulation in Parkinson's disease. Brain, 125, 575-583.

[21] Agid Y, Schüpbach M, Gargiulo M, Mallet L, Houeto JL, Behar C, Maltête D, Mesnage V, \& Welter ML (2006) Neurosurgery in Parkinson's disease: The doctor is happy, the patient less so? J Neural Transm Suppl, 70, 409-414.

[22] Schüpbach M, Gargiulo M, Welter ML, Mallet L, Béhar C, Houeto JL, Maltête D, Mesnage V, \& Agid Y (2006) Neurosurgery in Parkinson disease: A distressed mind in a repaired body? Neurology, 66, 1811-1816.

[23] Houeto JL, Mesnage V, Mallet L, Pillon B, Gargiulo M, du Moncel ST, Bonnet AM, Pidoux B, Dormont D, Cornu P, \& Agid Y (2002) Behavioural disorders, Parkinson's disease and subthalamic stimulation. J Neurol Neurosurg Psychiatry, 72, 701-707.

[24] Kulisevsky J, Berthier ML, Gironell A, Pascual-Sedano B, Molet J, \& Parés P (2002) Mania following deep brain stimulation for Parkinson's disease. Neurology, 59, 1421-1424.

[25] Voon V, Krack P, Lang AE, Lozano AM, Dujardin K, Schüpbach M, D'Ambrosia J, Thobois S, Tamma F, Herzog J, Speelman JD, Samanta J, Kubu C, Rossignol H, Poon YY, Saint-Cyr JA, Ardouin C, \& Moro E (2008) A multicentre study on suicide outcomes following subthalamic stimulation for Parkinson's disease. Brain, 131, 2720-2728.

[26] Cyron D (2016) Mental Side Effects of Deep Brain Stimulation (DBS) for Movement Disorders: The Futility of Denial. Front Integr Neurosci, 10, 17. doi: 10.3389/fnint.2016.00017 
[27] Hariz MI (2000) Pros and cons of various surgical procedures for Parkinson's disease. Pan Arab J Neurosurgery, 4, 18-24.

[28] Okun MS, \& Foote KD (2010) Parkinson's disease DBS: What, when, who and why? The time has come to tailor DBS targets. Expert Rev Neurother, 10, 1847-1857.

[29] Foltynie T, \& Hariz MI (2010) Surgical management of Parkinson's disease. Expert Rev Neurother, 10, 903-914.

[30] Williams NR, Foote KD, \& Okun MS (2014) STN vs. GPi Deep Brain Stimulation: Translating the Rematch into Clinical Practice. Mov Disord Clin Pract, 1, 24-35.

[31] Fox SH, Katzenschlager R, Lim SY, Ravina B, Seppi K, Coelho M, Poewe W, Rascol O, Goetz CG, \& Sampaio C (2011) The Movement Disorder Society evidence-based medicine review update: Treatments for the motor symptoms of Parkinson's disease. Mov Disord, 26, S2-S41.

[32] Hariz M (2012) Twenty-five years of deep brain stimulation: Celebrations and apprehensions. Mov Disord, 27, 930-933.

[33] Ory-Magne F, Brefel-Courbon C, Simonetta-Moreau M, Fabre N, Lotterie JA, Chaynes P, Berry I, Lazorthes Y, \& Rascol O (2007) Does ageing influence deep brain stimulation outcomes in Parkinson's disease? Mov Disord, 22, 1457-1463.

[34] Hariz MI (2004) Is Microelectrode recording necessary in movement disorder surgery? The case against. In Microelectrode recording in movement disorder surgery, Israel Z, Burchiel KJ, eds. Thieme, New York, pp. 197-207.

[35] McClelland S 3rd (2011) A cost analysis of intraoperative microelectrode recording during subthalamic stimulation for Parkinson's disease. Mov Disord 26, 1422-1427.

[36] Hariz MI (2000) Complications of Movement Disorder Surgery and How to Avoid Them. In Progress in Neurological Surgery, Vol 15, Movement Disorder Surgery, Lozano A, ed. Karger, Basel, pp. 246-265.

[37] Hariz MI (2011) Surgical probings into the basal ganglia: Hemorrhage and hardware-related risks, and costs of microelectrode recording. Mov Disord, 26, 1375-1377.

[38] Zrinzo L, Foltynie T, Limousin P, \& Hariz MI (2012) Reducing hemorrhagic complications in functional neurosurgery: A large case series and systematic literature review. J Neurosurg, 116, 84-94.

[39] Burchiel KJ, McCartney S, Lee A, \& Raslan AM (2013) Accuracy of deep brain stimulation electrode placement using intraoperative computed tomography without microelectrode recording. J Neurosurg, 119, 301-306.

[40] Mirzadeh Z, Chapple K, Lambert M, Evidente VG, Mahant P, Ospina MC, Samanta J, Moguel-Cobos G, Salins N, Lieberman A, Tröster AI, Dhall R, \& Ponce FA (2016) Parkinson's disease outcomes after intraoperative CTguided "asleep" deep brain stimulation in the globus pallidus internus. J Neurosurg, 124, 902-907.

[41] Hariz MI, Krack P, Melvill R, Jorgensen JV, Hamel W, Hirabayashi H, Lenders M, Wesslen N, Tengvar M, \& Yousry TA (2003) A Quick, and Universal Method for Stereotactic Visualization of the Subthalamic Nucleus Before and After Implantation of Deep Brain Stimulation Electrodes. Stereotact Funct Neurosurg, 80, 96-101.

[42] Zrinzo L (2011) MRI Guided and MRI Verified Deep Brain Stimulation: Accuracy, Safety and Efficacy, UCL PhD Dissertation, London, ISBN 978-0-9573504-0-3.

[43] Foltynie T, Zrinzo L, Martinez-Torres I, Tripoliti E, Petersen E, Holl E, Aviles-Olmos I, Jahanshahi M, Hariz M, \& Limousin P (2011) MRI-guided STN DBS in Parkinson's disease without microelectrode recording: Efficacy and safety. J Neurol Neurosurg Psychiatry, 82, 358-363.
[44] Krack P (2011) Subthalamic stimulation for Parkinson's disease: A new benchmark. J Neurol Neurosurg Psychiatry, 82 , 356-357.

[45] Deuschl G, Schade-Brittinger C, Krack P, Volkmann J, Schäfer H, Bötzel K, Daniels C, Deutschländer A, Dillmann U, Eisner W, Gruber D, Hamel W, Herzog J, Hilker R, Klebe S, Kloss M, Koy J, Krause M, Kupsch A, Lorenz D, Lorenzl S, Mehdorn HM, Moringlane JR, Oertel W, Pinsker MO, Reichmann H, Reuss A, Schneider GH, Schnitzler A, Steude U, Sturm V, Timmermann L, Tronnier V, Trottenberg T, Wojtecki L, Wolf E, Poewe W, Voges J; German Parkinson Study Group, Neurostimulation Section. (2006) A randomized trial of deep-brain stimulation for Parkinson's disease. N Engl J Med 355, 896-908.

[46] Williams A, Gill S, Varma T, Jenkinson C, Quinn N, Mitchell R, Scott R, Ives N, Rick C, Daniels J, Patel S, Wheatley K (2010) PD SURG Collaborative Group, Deep brain stimulation plus best medical therapy versus best medical therapy alone for advanced Parkinson's disease (PD SURG trial): A randomised, open-label trial. Lancet Neurol, 9, 581-591.

[47] Schüpbach WM, Maltête D, Houeto JL, du Montcel ST, Mallet L, Welter ML, Gargiulo M, Béhar C, Bonnet AM, Czernecki V, Pidoux B, Navarro S, Dormont D, Cornu P, Agid Y (2007) Neurosurgery at an earlier stage of Parkinson disease: A randomized, controlled trial. Neurology 68, 267271.

[48] Schuepbach WM, Rau J, Knudsen K, Volkmann J, Krack P, Timmermann L, Hälbig TD, Hesekamp H, Navarro SM, Meier N, Falk D, Mehdorn M, Paschen S, Maarouf M, Barbe MT, Fink GR, Kupsch A, Gruber D, Schneider GH, Seigneuret E, Kistner A, Chaynes P, Ory-Magne F, Brefel Courbon C, Vesper J, Schnitzler A, Wojtecki L, Houeto JL, Bataille B, Maltête D, Damier P, Raoul S, Sixel-Doering F, Hellwig D, Gharabaghi A, Krüger R, Pinsker MO, Amtage F, Régis JM, Witjas T, Thobois S, Mertens P, Kloss M, Hartmann A, Oertel WH, Post B, Speelman H, Agid Y, Schade-Brittinger C, \& Deuschl G; EARLYSTIM Study Group (2013) Neurostimulation for Parkinson's disease with early motor complications. N Engl J Med 368, 610-622.

[49] Hariz M (2013) Early surgery for Parkinson's disease? Maybe, but not just yet. Lancet Neurol, 12, 938-939.

[50] Mestre TA, Espay AJ, Marras C, Eckman MH, Pollak P, \& Lang AE (2014) Subthalamic nucleus-deep brain stimulation for early motor complications in Parkinson's disease-the EARLYSTIM trial: Early is not always better. Mov Disord, 29, 1751-1756.

[51] Charles D, Konrad PE, Neimat JS, Molinari AL, Tramontana MG, Finder SG, Gill CE, Bliton MJ, Kao C, Phibbs FT, Hedera P, Salomon RM, Cannard KR, Wang L, Song Y, \& Davis TL (2014) Subthalamic nucleus deep brain stimulation in early stage Parkinson's disease. Parkinsonism Relat Disord, 20, 731-737.

[52] Hariz M (2015) There is no credible rational for deep brain stimulation in very early Parkinson's disease! Parkinsonism Relat Disord, 21, 345-346.

[53] Okun MS, \& Foote KD (2005) Subthalamic nucleus vs globus pallidus interna deep brain stimulation, the rematch: Will pallidal deep brain stimulation make a triumphant return? Arch Neurol, 62, 533-536.

[54] Burchiel KJ, Anderson VC, Favre J, \& Hammerstad JP (1999) Comparison of pallidal and subthalamic nucleus deep brain stimulation for advanced Parkinson's disease: Results of a randomized, blinded pilot study. Neurosurgery, 45, 1375-1382. 
[55] Anderson VC, Burchiel KJ, Hogarth P, Favre J, \& Hammerstad JP (2005) Pallidal vs subthalamic nucleus deep brain stimulation in Parkinson disease. Arch Neurol, 62, 554-560.

[56] Bronstein JM (2015) Neuropsychological outcome after deep brain stimulation for Parkinson disease. Neurology, 85, 1433.

[57] Follett KA, Weaver FM, Stern M, Hur K, Harris CL, Luo P, Marks WJ Jr, Rothlind J, Sagher O, Moy C, Pahwa R, Burchiel K, Hogarth P, Lai EC, Duda JE, Holloway K, Samii A, Horn S, Bronstein JM, Stoner G, Starr PA, Simpson R, Baltuch G, De Salles A, Huang GD, Reda DJ; CSP 468 Study Group (2010) Pallidal versus subthalamic deepbrain stimulation for Parkinson's disease. N Engl J Med 362, 2077-2091.

[58] Vitek JL, Bakay RA, Freeman A, Evatt M, Green J, McDonald W, Haber M, Barnhart H, Wahlay N, Triche S, Mewes K, Chockkan V, Zhang JY, \& DeLong MR (2003) Randomized trial of pallidotomy versus medical therapy for Parkinson's disease. Ann Neurol, 53, 558-569.

[59] Lang AE, Lozano AM, Montgomery E, Duff J, Tasker R, \& Hutchinson W (1997) Posteroventral medial pallidotomy in advanced Parkinson's disease. N Engl J Med, 337, 10361042.

[60] Esselink RA, de Bie RM, de Haan RJ, Lenders MW, Nijssen PC, van Laar T, Schuurman PR, Bosch DA, \& Speelman JD (2009) Long-term superiority of subthalamic nucleus stimulation over pallidotomy in Parkinson disease. Neurology, $\mathbf{7 3}, 151-153$

[61] Hariz G, \& Hariz MI (2000) Gender distribution in surgery for Parkinson's disease. Parkinsonism Relat Disord, 6, 155157.

[62] Hariz GM, Nakajima T, Limousin P, Foltynie T, Zrinzo L, Jahanshahi M, \& Hamberg K (2011) Gender distribution of patients with Parkinson's disease treated with subthalamic deep brain stimulation; a review of the 2000-2009 literature. Parkinsonism Relat Disord, 17, 146-149.

[63] Hariz MI, \& Bergenheim AT (2001) A 10-year follow-up review of patients who underwent Leksell's posteroventral pallidotomy for Parkinson disease. J Neurosurg, 94, 552558.

[64] Hariz M (2012) Striking similarities between pallidotomy and STN DBS at very long-term follow-up. Mov Disord, 27, 806.

[65] Krack P, Batir A, Van Blercom N, Chabardes S, Fraix V, Ardouin C, Koudsie A, Limousin PD, Benazzouz A, LeBas JF, Benabid AL, \& Pollak P (2003) Five-year follow-up of bilateral stimulation of the subthalamic nucleus in advanced Parkinson's disease. N Engl J Med, 349, 1925-1934.

[66] Zibetti M, Merola A, Rizzi L, Ricchi V, Angrisano S, Azzaro C, Artusi CA, Arduino N, Marchisio A, Lanotte M, Rizzone M, \& Lopiano L (2011) Beyond nine years of continuous subthalamic nucleus deep brain stimulation in Parkinson's Disease. Mov Disord, 26, 2327-2334.

[67] Obeso JA, \& Olanow W (2011) Deep brain stimulation for Parkinson's disease: Thinking about the long-term in the short-term. Mov Disord, 26, 2303-2304.

[68] Bejjani BP, \& Nohra G (2008) The new phenotype of Parkinson's disease: The postsubthalamic stimulation era. Neurology, (7)(suppl 1), A179.

[69] Hariz M (2014) Deep brain stimulation: New techniques. Parkinsonism Relat Disord, 20(Suppl 1), S192-S196.

[70] Reker P, Dembek TA, Becker J, Visser-Vandewalle V, \& Timmermann L (2016) Directional deep brain stimulation: A case of avoiding dysarthria with bipolar directional current steering. Parkinsonism Relat Disord, 31, 156-158.

[71] Steigerwald F, Müller L, Johannes S, Matthies C, \& Volkmann J (2016) Directional deep brain stimulation of the subthalamic nucleus: A pilot study using a novel neurostimulation device. Mov Disord, 31, 1240-1243.

[72] Volkmann J, Chabardes S, Steinke GK, \& Carcieri S (2016) 375 DIRECT DBS: A Prospective, Multicenter Clinical Trial With Blinding for a Directional Deep Brain Stimulation Lead. Neurosurgery, 63(Suppl 1), 211-212.

[73] Chen CC, Brücke C, Kempf F, Kupsch A, Lu CS, Lee ST, Tisch S, Limousin P, Hariz M, \& Brown P (2006) Deep brain stimulation of the subthalamic nucleus: A two-edged sword. Curr Biol, 16, R952-R953.

[74] Little S, Pogosyan A, Neal S, Zavala B, Zrinzo L, Hariz M, Foltynie T, Limousin P, Ashkan K, FitzGerald J, Green AL, Aziz TZ, \& Brown P (2013) Adaptive deep brain stimulation in advanced Parkinson disease. Ann Neurol, 74, 449-457.

[75] Little S, Beudel M, Zrinzo L, Foltynie T, Limousin P, Hariz M, Neal S, Cheeran B, Cagnan H, Gratwicke J, Aziz TZ, Pogosyan A, \& Brown P (2016) Bilateral adaptive deep brain stimulation is effective in Parkinson's disease. $\mathrm{J} \mathrm{Neu}$ rol Neurosurg Psychiatry, 87, 717-721.

[76] Little S, Tripoliti E, Beudel M, Pogosyan A, Cagnan H, Herz D, Bestmann S, Aziz T, Cheeran B, Zrinzo L, Hariz M, Hyam J, Limousin P, Foltynie T, Brown P (2026) Adaptive deep brain stimulation for Parkinson's disease demonstrates reduced speech side effects compared to conventional stimulation in the acute setting. J Neurol Neurosurg Psychiatry, 2016 Aug 16. pii: jnnp-2016-313518. doi: 10.1136/jnnp2016-313518. [Epub ahead of print]

[77] Blomstedt P (2007) Analysis of deep brain stimulation and ablative lesions in surgical treatment of movement disorders, with emphasis on safety aspects, Umeå University Medical Dissertations, Umeå, ISBN 91-7264-210-6.

[78] Gross RE (2008) What happened to posteroventral pallidotomy for Parkinson's disease and dystonia? Neurotherapeutics, 5, 281-293. 